\title{
Chilling resistance of corn and cold stress responses of salicylic acid-treated corn
}

\author{
Xilin Ning, Xiaohui Wang, Yue Cui, Xiao Li, Yan Gu*, Chunsheng Wu* \\ Agricultural College, Jilin Agricultural University, Changchun, Jilin 130118 China \\ *Corresponding authors, e-mail: guyan8619@sina.com, wuchunsheng@jlau.edu.cn
}

Received 12 Jun 2020

Accepted 24 Jun 2021

\begin{abstract}
Breeding chilling-resistant corn coupled with the use of exogenous hormones to mitigate the damage caused by stress is important in successful corn farming. Here, we evaluated the germination rate of 45 corn varieties and profiled their chilling resistance level. Besides, to determine the effect of salicylic acid (SA) treatment on plants under cold stress, we treated the corn with SA and then selected chilling-resistant and chilling-sensitive varieties. Our data demonstrated that the germination energy (GE), germination percentage (GP), and germination index (GI) for most of the cold treated corn varieties were lower than those of the control group. The membership function (MF) and D-value results showed that HengYu709 was a chilling resistant corn variety while DongDan213 was sensitive to the chilling stimuli. Furthermore, treatment with SA enhanced the chilling resistance in both HengYu709 and DongDan213. In addition, the data showed that 0.5 or $1.0 \mathrm{mmol} / 1 \mathrm{SA}$ treatment significantly increased photosynthesis and oxidase activity in corn under cold stress. However, a high concentration of SA could reduce the photosynthesis indexes. Taken together, our data demonstrate that SA treatment could alleviate the effect of cold stress in corn growth and development.
\end{abstract}

KEYWORDS: chilling stress, germination, salicylic acid, chilling resistance, maize

\section{INTRODUCTION}

Corn (Maize), a major food crop in many parts of the world [1], is the third most important food crop in China after wheat and rice [2]. Since corn is a warm-climate plant, chilling is one of the abiotic stimuli that influences its growth and development [3]. Therefore, effective measures to mitigate the damage caused by cold stress are crucial in corn production. The sensitivity of corn to temperature depends on the developmental stage. It has been reported that abiotic stress leads to accumulation of reactive oxygen species (ROS), which may cause oxidative damage in plant cells $[4,5]$. Under natural and robust artificial selection, plants have gradually developed defense mechanisms against oxidative stress [6]. With the development of various planting technologies, the use of exogenous hormones has proven effective in the alleviation of the damage caused by abiotic stress [7].

Salicylic acid (SA) is an endogenous regulator of plant metabolism and plays various roles in physiological and metabolic processes in plant cells [8]. Exogenous application of SA regulates the functions of antioxidative enzymes and escalates plant tolerance to abiotic stresses [9]. In addition, SA participates in the signaling processes associated with abiotic stress responses such as high or low temperatures, drought, or salinity [10]. Besides, previous studies have shown that SA pre-treatment could considerably counter the harmful impact of heat and high light stress on PSII in wheat leaves as well as stimulation of photosynthetic functions [11]. In addition, SA treatment can alleviate the damage caused by low temperatures. The effect of SA on low temperature stress was first demonstrated by addition of $0.5 \mathrm{mM}$ SA to the hydroponic growth solution of maize seedlings under normal growth conditions. The data showed that SA substantially reduced damage of maize in subsequent chilling stress [12]. Besides, SA treatment increased the activity of glutathione reductase and guaiacol peroxidase, which could partially explain the increased cold tolerance [13]. To cope up with excessive production of ROS in plant cells, the activities of the superoxide dismutase (SOD), peroxidase (POD), and catalase (CAT) were shown to be activated in plant leaves under chilling stress [14]. Xu et al [15] noted that different varieties have different enzyme-specific oxidation activities in response to the chilling stress. Because higher activities of antioxidant enzymes and higher content of non-enzymatic antioxidants under stress are associated with genotype-dependent tolerance to chilling, it is important to evaluate the response of different crop cultivars to abiotic stress [16]. However, data on the use of SA to resist low temperature stress in crop production, especially corn, remain scant. Besides, there is limited knowledge on the response of different corn varieties to SA. Here, we tested the germination rate of 45 corn varieties and profiled their chilling resistance levels. We then subjected the chilling-resistant and chilling-sensitive varieties to SA treatment in order to evaluate the effect of SA treatment on plants under cold stress. We aimed to unearth an effective method that could be used in ranking cold resistance and reveal the genotype differences between cold-resistant and 
cold-sensitive corn varieties under chilling stress.

\section{MATERIALS AND METHODS}

\section{Assessment of low-temperature resistance}

This study was conducted at the Crop Research Center of Jilin Agricultural University, Changchun, China. To screen cold-tolerant corn varieties, a total of 45 corn varieties in Northeast China were collected (Table S1). The corn seeds were surface sterilized in $1 \%$ sodium hypochlorite for $10 \mathrm{~min}$ and then washed with distilled water. Corn seed germination was evaluated by randomly placing 20 seeds in a petri dish $(9 \mathrm{~cm}$ in diameter) containing 3 filter papers moistened with distilled water. A total of 9 germination dishes were randomly set up and placed in 3 artificial climate chambers. The experiment was conducted in triplicate with 20 repetitions in each artificial climate chamber. The light/dark (12 h/12 h) cycles, relative humidity (RH, 100\%), or light intensity (100 lx) in the 3 artificial climate chambers were kept constant. On the other hand, the temperature of the 3 artificial climate boxes was set to $10^{\circ} \mathrm{C}$ (group $10^{\circ} \mathrm{C}$ ), $15^{\circ} \mathrm{C}$ (group $15^{\circ} \mathrm{C}$ ), or $25^{\circ} \mathrm{C}$ (group control) as shown in Fig. S1. The germination energy (GE, the percentage of normal germinated seeds in all tested seeds at the 3rd day), germination percentage (GP, the percentage of normal germinated seeds in all tested seeds at the end of the test) $[17]$, and GI $\left(\left[\mathrm{G}_{1} / 1\right]+\left[\mathrm{G}_{2} / 2\right]+\ldots+\left[\mathrm{G}_{x} / x\right]\right)$; where $\mathrm{G}$ is the germination day $1,2, \ldots$, and $x$ represents the corresponding day of germination [18] were calculated. Based on the germination test data, we determined the low-temperature resistance grade.

\section{Corn treatment with salicylic acid}

Following the corn germination tests, cold-tolerant (HengYu709) or cold-sensitive (DongDan213) corn was treated with SA to evaluate its ability to shield the plants from cold stress. A total of $160 \mathrm{HengYu709}$ and 160 DongDan213 corn plants were used in this study. Seeds were sown in plastic soil-filled pots with each pot having single seedlings. The soil substrate had $\mathrm{pH}$ 6.8, organic matter (OM) $12.1 \mathrm{~g} / \mathrm{kg}$, total nitrogen (TN) $1.093 \mathrm{~g} / \mathrm{kg}$, total phosphorus (TP) $381.83 \mathrm{mg} / \mathrm{kg}$, alkaline hydrolyzable nitrogen (AhN) $65.27 \mathrm{mg} / \mathrm{kg}$, available phosphorus (AP) $10.68 \mathrm{mg} / \mathrm{kg}$, and available potassium (AK) $103.84 \mathrm{mg} / \mathrm{kg}$. Conventional fertilization was implemented during planting such as the application of $2.5 \mathrm{~g}$ of urea, $1.2 \mathrm{~g}$ of diammonium phosphate, and $1 \mathrm{~g}$ of potassium chloride. At the booting stage, 150 plant samples from each variety were randomly divided into 5 groups (10 biological repeats in each) and then sprayed with 5 different concentrations of SA: 0.0 (control group, marked as CK), $0.5,1.0,1.5$, or $2.0 \mathrm{mmol} / 1 ; 3$ times a day $(20 \mathrm{ml}$ per day). After 2 days of SA treatment, the plants were randomly divided into 2 groups (5 plants in each group). One group was placed in an artificial climate chamber at $10^{\circ} \mathrm{C}$ while the other was placed in an artificial climate chamber at $15^{\circ} \mathrm{C}$. After 5 days of stress, the flag leaves of the plants were harvested for subsequent experiments (Fig. S2).

\section{Leaf gas exchange measurement}

To test for the presence of measurement biases in the introduced $\mathrm{T}_{\text {leaf }}-\mathrm{T}_{\text {air }}$, net photosynthetic rate $(\mathrm{Pn})$, transpiration rate ( $\mathrm{Tr}$ ), and stomatal conductance (Gs) were measured by LI-6400 XT portable photosynthesis system (LI-COR, Lincoln, NE, USA) with expanded temperature control kits.

\section{Measurement of chlorophyll fluorescence parameters}

The leaves were used for gas exchange measurement, and chlorophyll fluorescence parameters were evaluated using a pulse modulation fluorometer (FMS2, Hansatech, UK) following the previously described protocol by Yin et al [19]. Before the chlorophyll fluorescence assays, the plants were dark-adapted for $25 \mathrm{~min}$. Minimum fluorescence $\left(\mathrm{F}_{0}\right)$ was measured with a beam of light having an intensity of less than $0.05 \mu \mathrm{mol} / \mathrm{m}^{2} \mathrm{~s}$. On the other hand, maximum fluorescence $\left(\mathrm{F}_{\mathrm{m}}\right)$ was obtained by measuring chlorophyll fluorescence during a $2.5 \mathrm{~s}$ pulse of saturating light (18000 $\left.\mu \mathrm{mol} / \mathrm{m}^{2} \mathrm{~s}\right)$. Maximal PSII photochemical efficiency $\left(\mathrm{F}_{\mathrm{v}} / \mathrm{F}_{\mathrm{m}}\right)$ and variable fluorescence $\left(\mathrm{F}_{\mathrm{v}}\right)$ were also recorded [20]. The quantum efficiency of PSII (ФPSII) was calculated using $\left(\mathrm{F}_{\mathrm{m}}^{\prime} \pm \mathrm{F}_{\mathrm{s}}\right) / \mathrm{F}_{\mathrm{m}}^{\prime}$ [21] while photochemical quenching (qP) was calculated using $\left(\mathrm{F}_{\mathrm{m}}^{\prime} \pm \mathrm{F}_{\mathrm{s}}\right) /\left(\mathrm{F}_{\mathrm{m}}^{\prime} \pm \mathrm{F}_{0}\right)[22]$.

\section{Determination of SOD, POD, and CAT}

Enzyme activity was determined in $0.1 \mathrm{~g}$ of the leaves. Superoxide dismutase (SOD) activity was detected based on the inhibition of the photochemical reduction of nitro blue tetrazolium (NBT) [23]. Catalase (CAT) activity was obtained spectrophotometrically by measuring the decomposition of $45 \mu \mathrm{M} \mathrm{H}_{2} \mathrm{O}_{2}$ in $0.05 \mathrm{M}$ phosphate buffer ( $\mathrm{pH} \mathrm{7.0)}$ at $240 \mathrm{~nm}$ [24]. On the other hand, peroxidase (POD) activity was estimated spectrophotometrically by measuring the increase in absorbance of the product of the reaction in $30 \% \mathrm{H}_{2} \mathrm{O}_{2}$, 99\% 2-methoxyphenol, and $0.05 \mathrm{M}$ phosphate buffer (pH 6.0) at $470 \mathrm{~nm}$ [24]. In addition, we adopted the glucosinolates barbituric acid colorimetric method to determine Malondialdehyde (MDA) content [25]. Antioxidant enzyme activities and MDA content were determined following the instruction in the assay kit.

\section{Comprehensive evaluation}

Membership function (MF) and D-values were used to assess the seed germination chilling resistance index, following the previously described protocols [26, 27]. Besides, the relative trait values (RTV), \% RTV = $\mathrm{X}_{\mathrm{L}} / \mathrm{X}_{\mathrm{N}} \times 100 \%$, were also calculated. $\mathrm{X}_{\mathrm{L}}$ represents 
the index value measured at low temperature while $\mathrm{X}_{\mathrm{N}}$ represents the index value measured at normal temperature.

\section{RESULTS}

\section{Relative trait values (RTV) for GE, GP, and GI}

To test the chilling stress response, we subjected the corn seedlings to low temperature stimuli. Our analysis showed that at $15^{\circ} \mathrm{C}$, the GE, GP, or GI values of most of the plants decreased compared with the control (RTV < 100\%). However, several indicators in some plant materials were improved compared to the control (RTV > 100\%) (Table S1). DongDan213 had the highest GE value while ChangDan297 had the lowest $\mathrm{GE}$ value at $15^{\circ} \mathrm{C}$. On the other hand, JunDan6 and HengYu709 had the highest GI values while $L v Y u 4117$ and DongDan213 had the lowest GI values of all the varieties. Germination tests at $10^{\circ} \mathrm{C}$ showed that HengYu709 and LiangYu99 had the highest and lowest GE, GP, and GI values, respectively. Besides, HengYu709 had a relatively high GI value at $15^{\circ} \mathrm{C}$ and $10^{\circ} \mathrm{C}$. Thus, it was feasible to speculate that HengYu709 has a strong tolerance to cold stress during germination. Interestingly, while DongDan213 had the highest RTV for GE value at $15^{\circ} \mathrm{C}$, the values decreased sharply at $10^{\circ} \mathrm{C}$. In addition, the DongDan 213 GI value was relatively low. Taken together, we show that DongDan213 was sensitive to cold stress during germination.

\section{Membership function (MF) for GE, GP, and GI}

To increase the confidence in the evaluation data, the membership function was established based on the GE, GP, and GI values. The larger the MF value, the stronger the resistance of the variety to cold stimuli. At $15^{\circ} \mathrm{C}$, Jundan6, ChuangShi998, LiMin33, HW217, JiuDan100, LiNong24, DayuM737, JiDan33, HengYu709, and TieYan36 had higher GI values, thus these varieties were more resistant to cold stress. On the other hand, JiDan137, PingAn185, WeiKe3757, XianYu335, MeiHeDa529, W1521, JiDan50, LiangYu88, FuYou10, and LuYu4117 showed sensitivity to the low-temperature stress at $15^{\circ} \mathrm{C}$ (Table S2). Further reduction of the temperature $\left(10^{\circ} \mathrm{C}\right)$ led to higher GI values in Hengyu709, DaYuM737, JiNongDa885, LiMin33, JiDan47, ZhengDan958, JiDan550, HW217, $\mathrm{HeYu3}$, and JiDan87, demonstrating more resistance to the cold stress. Conversely, XianYu335, ChangDan297, JiDan33, XianYu508, LuYu4117, LuAo150, LiangYu88, FuYou10, LiangYu66, and LiangYu99 were susceptible to the cold stress at $10^{\circ} \mathrm{C}$ (Table S2).

\section{Comprehensive evaluation of the cold tolerance using D-value}

Comprehensive evaluation value or recovery index (D) for cold tolerance was computed at germination. Based on the D-value, the cold-tolerance capacity for every variety can be ranked; the larger the value of $\mathrm{D}$, the stronger the cold tolerance. Among the examined varieties, HengYu709 had the greatest mean D-value (6.96) while $L v Y u 4117$ had the lowest mean D-value (0.8). Clustering of the varieties based on the D-values showed that HengYu709, DaYuM737, and JiDan47 belonged to level I; YanFeng508 and ZhengDan958 belonged to level II; DongDan213 and DeDan1002 belonged to level III while LiangYu66 and LiangYu99 were clustered in level IV (Fig. 1). Taken together, data from the 3 evaluation indexes robustly demonstrated that HengYu709 was more resistant to a low-temperature environment while DongDan213 was more sensitive to the low temperatures.

\section{Effects of salicylic acid treatment on leaf gas exchange}

Here, we used HengYu709 and DongDan213 to assay the effect of SA treatment on the plants' response to cold. Cold stress significantly decreased the Pn value of flag leaves of both corn varieties; the lower the temperature, the lower the Pn value. An appropriate concentration of SA treatment was shown to significantly alleviate the decrease of Pn caused by the low temperature stress. At $15^{\circ} \mathrm{C}$, the plants' Pn value peaked at $0.5 \mathrm{mmol} / 1 \mathrm{SA}$ treatment while at $10^{\circ} \mathrm{C}$, HengYu709 and DanDong213 attained Pn value peaks at 1.0 and $1.5 \mathrm{mmol} / \mathrm{l} \mathrm{SA}$ treatment, respectively. For the cold-sensitive variety, the Pn value of DanDong213 at $15^{\circ} \mathrm{Cwas}$ significantly increased with $0.5 \mathrm{mmol} / 1$ SA treatment compared with $0 \mathrm{mmol} / \mathrm{l}$, which was even higher than that at normal temperature (Fig. 2a). However, too high concentrations of SA lead to decreased Pn values. The Tr values showed similar trends as the Pn values. Cold stress reduced the Tr values for both corn varieties. Whereas the Tr value increased under low-temperature stress, it decreased after exceeding $1.0 \mathrm{mmol} / \mathrm{m}^{2} \mathrm{~s}$ (Fig. $2 \mathrm{~b}$ ). In addition, the Gs value for the plants at $15^{\circ} \mathrm{C}$ peaked at $0.5 \mathrm{mmol} / 1 \mathrm{SA}$ treatment. Importantly, the Gs values for HengYu709 and DanDong213 peaked at 1.0 and $1.5 \mathrm{mmol} / 1 \mathrm{SA}$ treatment, respectively, at $10^{\circ} \mathrm{C}$ (Fig. 2c).

\section{Effects of salicylic acid treatment on chlorophyll fluorescence parameters}

An increased concentration of SA at $15^{\circ} \mathrm{C}$ led to the initial rise of $\mathrm{F}_{\mathrm{v}} / \mathrm{F}_{\mathrm{m}}, \Phi P S I I$, and $\mathrm{qP}$ values, which declined afterwards. Treatment with $0.5 \mathrm{mmol} / 1 \mathrm{SA}$ had the largest value of chlorophyll fluorescence parameters. There was, however, a negative effect when the SA concentration was increased to $2.0 \mathrm{mmol} / \mathrm{l}$. No significant difference was found in $\mathrm{F}_{\mathrm{v}} / \mathrm{F}_{\mathrm{m}}$, $\Phi$ PSII, or $\mathrm{qP}$ between the 2 corn varieties at a given SA concentration (Fig. 3). At $10^{\circ} \mathrm{C}$, the $\mathrm{F}_{\mathrm{v}} / \mathrm{F}_{\mathrm{m}}$ and $\Phi$ PSII values increased significantly compared with the unsprayed control. Furthermore, at the $10^{\circ} \mathrm{C}$ environment coupled with the increased SA concentration, 


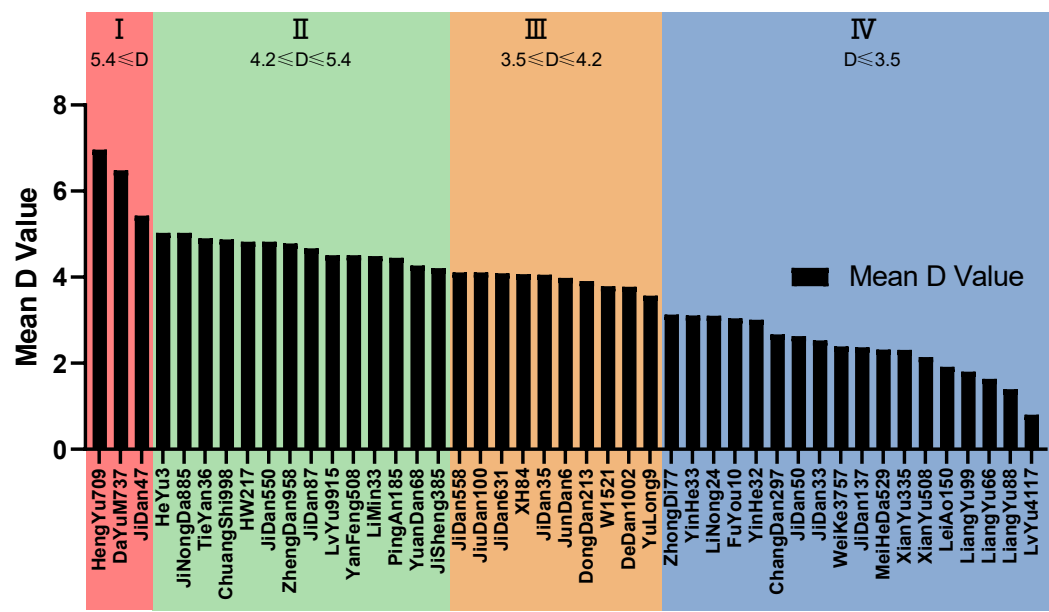

\section{Varieties}

Fig. 1 D-value evaluation of corn germination index. Different colors indicate different chilling resistance grades.


Fig. 2 Effects of salicylic acid on gas exchange parameters of corn leaves under chilling stress.

Fig. 3 Effects of salicylic acid on chlorophyll fluorescence parameters of corn leaves under chilling stress.

or $1.5 \mathrm{mmol} / 1 \mathrm{SA}$ treatment in Hengyu709 or DongDan213, respectively. In the $0-1.0 \mathrm{mmol} / 1 \mathrm{SA}$ treatthe $\mathrm{F}_{\mathrm{v}} / \mathrm{F}_{\mathrm{m}}$, $\Phi$ PSII, or $\mathrm{qP}$ value showed initial increase before a decline. At $10^{\circ} \mathrm{C}$, the $\mathrm{qP}$ value peaked at 1.0 

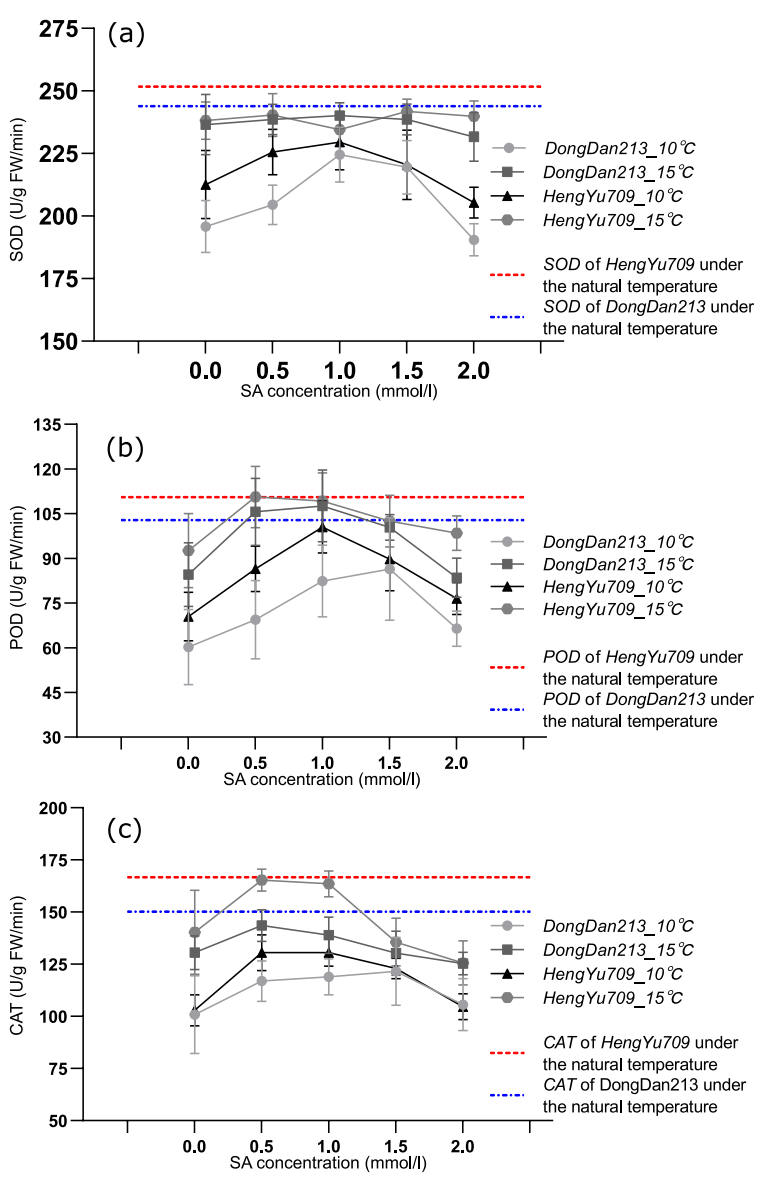

Fig. 4 Effects of salicylic acid on protective enzyme activities of maize leaves under chilling stress.

significantly higher than that of the DongDan213 at a given concentration (Fig. 3).

\section{Effects of salicylic acid treatment on SOD, POD, and CAT}

There was no significant difference in the SOD activity between the 2 corn varieties under normal conditions. The POD and CAT activities in HengYu709 were significantly higher than those in the DongDan213. Besides, treatment with SA at $15^{\circ} \mathrm{C}$ had little effects on leaf SOD activity. However, $0.5 \mathrm{mM}$ of SA treatment could significantly increase leaf POD and CAT activities. Moreover, at $10^{\circ} \mathrm{C}$ coupled with the increased SA concentration, there was initial rise of SOD and POD activities, followed by a decline (Fig. 4).

\section{DISCUSSION}

Bud formation is one of the most sensitive stages to temperature in the growth and development of corn. Previous studies reported that identification of cold tolerance at bud formation might reflect field experiment [28]. On the other hand, seed germination is a dynamic and ordered process involving several biochemical pathways [29], which can be affected by abiotic stresses. Here, we evaluated the germination efficiency of different varieties of corn and their response to abiotic stimuli. The germination tests showed that the GE, GP, and GI values of most coldexposed corn varieties were lower than those in the control group, indicating that cold stress has a negative impact on seed germination. Interestingly, at $15^{\circ} \mathrm{C}$, the GE, GP, and GI values of some varieties was even higher than those at $25^{\circ} \mathrm{C}$ but declined sharply at $10^{\circ} \mathrm{C}$. Thus, the GE, GP, and GI values are not sufficient in the assessment of cold resistance. To better dissect the response, we used the MF and D-value methods, which had been used in previous studies [30,31]. The $\mathrm{MF}$ and D-value data was consistent with the cold resistance profile of the plants. Using the D-value data, we classified all the corn varieties into 4 grades, which were close to the production practices.

We then used SA to gain more insights into the role of hormones in plant growth. SA, an omnipresent plant growth hormone with additive effects on plant growth and development, can increase photosynthetic rate [32], regulate the antioxidant defense system through alleviation of oxidative stress [10], and improve PRO production [33]. To interrogate the effects of cold stress as well as the SA regulation on photosynthesis, we investigated gas exchange together with chlorophyll fluorescence parameters. Our data revealed that the corn plants, especially lowtemperature sensitive corn (DongDan213), subjected to cold stress experience sharp decline in photosynthesis. Besides, under a low temperature environment, most of the varieties showed a significant decrease in Pn value [34]. It has been reported that SA treatment could enhance low temperature resistance in many plant species such as rice, maize, wheat, and potato [35]. Sayyari et al [36] showed that exogenous application of SA can increase growth parameters and chlorophyll content in watermelon exposed to low temperatures, which was consistent with our findings. However, too high concentrations of SA reduced the photosynthesis indexes of the corn varieties under study. Previous studies reported that the Arabidopsis SA hyperaccumulation mutants showed susceptibility to cold stress, which might be due to the cell elongation and reduced cell proliferation [37]. In their study, Yang et al [38] reported that high concentrations of exogenous SA could reduce the activity of antioxidant enzymes, which weakened the ability of watermelon to confer resistance to cold. Similarly, our data showed that the treatment with $2.0 \mathrm{mmol} / \mathrm{l}$ of SA could reduce the activity of SOD, PRO, or CAT [38]. In addition, we found that 0.5 or $1.0 \mathrm{mmol} / 1 \mathrm{SA}$ treatment significantly increased photosynthesis and oxidase activity in corn under cold stress. Upon subjection to cold stress, there was accumulation of reactive oxygen species (ROS) in 
plant cells which could further induce membrane lipid peroxidation, thus leading to cell death or stagnation of plant growth and development [39]. The use of SA on cucumber seedlings under cold stress was shown to inhibit the accumulation of $\mathrm{H}_{2} \mathrm{O}_{2}$ [40]. Exogenous SA activates the antioxidant enzymes which remove excess $\mathrm{H}_{2} \mathrm{O}_{2}$, thus improving the cold resistance by the cucumber seedlings. Under cold stress, maize varieties with high cold resistance activate their own resistance to adversity. The cold resistant corn consumes excess light energy through processes such as the lutein cycle or photorespiration to form self-protection. However, under strong cold stress, parts of the PSII response centers in corn leaves were damaged, which hindered their growth and development. In agreement with previous observations [41], we showed that SA treatment could alleviate the effects of cold stress and improve photosynthesis in corn.

\section{CONCLUSION}

Taken together, our data demonstrates that evaluation of seed germination rate at low temperature can reflect the chilling resistance of corn varieties. Besides, the use of comprehensive evaluation D-value method closely illuminates the production practice experience. In addition, SA treatment can significantly improve the cold tolerance of different corn varieties.

\section{Appendix A. Supplementary data}

Supplementary data associated with this article can be found at http://dx.doi.org/10.2306/scienceasia1513-1874. 2022.018.

\section{REFERENCES}

1. Saliu BK, Sani A (2012) Bioethanol potentials of corn cob hydrolysed using cellulases of Aspergillus niger and Penicillium decumbens. EXCLI J 11, 468-479.

2. Li Y, Liu X, Hao T, Chen S (2017) Colonization and maize growth promotion induced by phosphate solubilizing bacterial isolates. Int J Mol Sci 18, 1253.

3. Kalisz A, Sȩkara A, Pokluda R, Jezdinský A, Neugebauerová J, Slezák KA, Kunicki E (2019) Sequential response of sage antioxidant metabolism to chilling treatment. Molecules 24, ID 4087.

4. Suzuki N, Mittler R (2006) Reactive oxygen species and temperature stresses: A delicate balance between signaling and destruction. Physiol Plant 126, 45-51.

5. Xue-Taoa Y, Fu-Pinga L, Hai-Honga G (2020) Effects of high temperature on photosynthetic capacity in the leaves of creepers. ScienceAsia 46, 436-443.

6. Shanker A, Shanker C (2016) Abiotic and Biotic Stress in Plants: Recent Advances and Future Perspectives, IntechOpen, London.

7. Kurepin LV, Ivanov AG, Zaman M, Pharis RP, Allakhverdiev SI, Hurry V, Hüner NPA (2015) Stress-related hormones and glycinebetaine interplay in protection of photosynthesis under abiotic stress conditions. Photosynth Res 126, 221-235.

8. Wu Z, Han S, Zhou H, Tuang ZK, Wang Y, Jin Y, Shi H, Yang W (2019) Cold stress activates disease resistance in
Arabidopsis thaliana through a salicylic acid dependent pathway. Plant Cell Environ 42, 2645-2663.

9. Parashar A, Yusuf M, Fariduddin Q, Ahmad A (2014) Salicylic acid enhances antioxidant system in Brassica juncea grown under different levels of manganese. Int $J$ Biol Macromol 70, 551-558.

10. Shah Jahan M, Wang Y, Shu S, Zhong M, Chen Z, Wu J, Sun J, Guo S (2019) Exogenous salicylic acid increases the heat tolerance in tomato (Solanum lycopersicum L) by enhancing photosynthesis efficiency and improving antioxidant defense system through scavenging of reactive oxygen species. Sci Hortic 247, 421-429.

11. Zhao H-J, Zhao X-J, Ma P-F, Wang Y-X, Hu W-W, Li LH, Zhao Y-D (2011) Effects of salicylic acid on protein kinase activity and chloroplast D1 protein degradation in wheat leaves subjected to heat and high light stress. Acta Ecologica Sinica 31, 259-263.

12. Janda T, Szalai G, Tari I, Páldi E (1999) Hydroponic treatment with salicylic acid decreases the effects of chilling injury in maize (Zea mays L.) plants. Planta 208, 175-180.

13. Pál M, Orsolya Kinga G, Janda T (2013) Role of salicylic acid in acclimation to low temperature. Acta Agronomica Hungarica 61, 161-172.

14. Janská A, Maršík P, Zelenková S, Ovesná J (2010) Cold stress and acclimation - what is important for metabolic adjustment? Plant Biology 12, 395-405.

15. Xu P-L, Guo Y-K, Bai J-G, Shang L, Wang X-J (2008) Effects of long-term chilling on ultrastructure and antioxidant activity in leaves of two cucumber cultivars under low light. Physiol Plant 132, 467-478.

16. Huang M, Guo Z (2005) Responses of antioxidative system to chilling stress in two rice cultivars differing in sensitivity. Biol Plant 49, 81-84.

17. Tanaka-Oda A, Kenzo T, Fukuda K (2009) Optimal germination condition by sulfuric acid pretreatment to improve seed germination of Sabina vulgaris Ant. $J$ Forest Res 14, 251-256.

18. Esechie HA (1994) Interaction of salinity and temperature on the germination of sorghum. J Agron Crop Sci 172, 194-199.

19. Yin C, Wang X, Duan B, Luo J, Li C (2005) Early growth, dry matter allocation and water use efficiency of two sympatric Populus species as affected by water stress. Environ Exp Bot 53, 315-322.

20. Zhang YJ, Gao H, Li YH, Wang L, Kong DS, Guo YY, Yan F, Wang YW, et al (2019) Effect of water stress on photosynthesis, chlorophyll fluorescence parameters and water use efficiency of common reed in the hexi corridor. Russ J Plant Physiol 66, 556-563.

21. Genty B, Briantais J-M, Baker NR (1989) The relationship between the quantum yield of photosynthetic electron transport and quenching of chlorophyll fluorescence. Biochim Biophys Acta Gen Subj 990, 87-92.

22. Bilger W, Schreiber U, Bock M (1995) Determination of the quantum efficiency of photosystem II and of nonphotochemical quenching of chlorophyll fluorescence in the field. Oecologia 102, 425-432.

23. Rico CM, Morales MI, McCreary R, Castillo-Michel H, Barrios AC, Hong J, Tafoya A, Lee W-Y, et al (2013) Cerium oxide nanoparticles modify the antioxidative stress enzyme activities and macromolecule composition in rice seedlings. Environ Sci Technol 47, 14110-14118. 
24. Bergmeyer HU (1974) Methods of Enzymatic Analysis, 2nd edn, Academic Press, Cambridge, MA, USA.

25. HeshengLi (2000) Principles and Techniques of Plant Physiological Biochemical Experiment, Higher Education Press, Beijing.

26. Zhou G, Mei F, Zhou Z, Zhu X (2003) Comprehensive evaluation and forecast on physiological indices of waterlogging resistance of different wheat varieties. Zhongguo Nong Ye Ke Xue 36, 1378-1382.

27. Liu M, Wang Z, Xiao H-m, Yang Y (2018) Characterization of TaDREB1 in wheat genotypes with different seed germination under osmotic stress. Hereditas 155, ID 26.

28. Wen-feng Z, Xin-juan W, Meng Y, Wan-rong G, Zhengjin X, Jing L (2013) Influence of low-temperature stress on photosynthetic traits in maize seedlings. $J$ Northeast Agric Univ 20, 1-5.

29. Luo T, Xian M, Zhang C, Zhang C, Hu L, Xu Z (2019) Associating transcriptional regulation for rapid germination of rapeseed (Brassica napus L.) under low temperature stress through weighted gene co-expression network analysis. Sci Rep 9, ID 55.

30. Xue L, Ma J, Wu J, Zhao C, Liu H, Liu D, Ma J (2019) Comprehensive evaluation on the tolerance of eight crop species to $\mathrm{CO}_{2}$ leakage from geological storage. Int $J$ Agric Biol 22, 561-568.

31. Xu W, Xiang P, Liu X, Ma LQ (2020) Closely-related species of hyperaccumulating plants and their ability in accumulation of $\mathrm{As}, \mathrm{Cd}, \mathrm{Cu}, \mathrm{Mn}, \mathrm{Ni}, \mathrm{Pb}$ and $\mathrm{Zn}$. Chemosphere 251, ID 126334.

32. Khan W, Prithiviraj B, Smith DL (2003) Photosynthetic responses of corn and soybean to foliar application of salicylates. J Plant Physiol 160, 485-492.

33. Iqbal N, Fatma M, Khan NA, Umar S (2019) Regulatory role of proline in heat stress tolerance: Modulation by salicylic acid. In: Plant Signaling Molecules, Woodhead Publishing, Cambridge, pp 437-448.

34. Yang XL, Xu H, Li D, Gao X, Li TL, Wang R (2018) Effect of melatonin priming on photosynthetic capacity of tomato leaves under low-temperature stress. Photosynthetica 56, 884-892.

35. Mora-Herrera ME, López-Delgado $\mathrm{H}$, Castillo-Morales A, Foyer CH (2005) Salicylic acid and $\mathrm{H}_{2} \mathrm{O}_{2}$ function by independent pathways in the induction of freezing tolerance in potato. Physiol Plant 125, 430-440.

36. Sayyari M, Ghanbari F, Fatahi S, Bavandpoor F (2013) Chilling tolerance improving of watermelon seedling by salicylic acid seed and foliar application. Notulae Scientia Biologicae 5, 67-73.

37. Miura K, Ohta M (2010) SIZ1, a small ubiquitin-related modifier ligase, controls cold signaling through regulation of salicylic acid accumulation. J Plant Physiol 167, 555-560.

38. Jing-Hua Y, Yuan G, Yan-Man L, Xiao-Hua Q, Zhang MF (2008) Salicylic acid-induced enhancement of cold tolerance through activation of antioxidative capacity in watermelon. Sci Hortic 118, 200-205.

39. Gill SS, Tuteja N (2010) Reactive oxygen species and antioxidant machinery in abiotic stress tolerance in crop plants. Plant Physiol Biochem 48, 909-930.

40. Dong C-J, Li L, Shang Q-M, Liu X-Y, Zhang Z-G (2014) Endogenous salicylic acid accumulation is required for chilling tolerance in cucumber (Cucumis sativus L.) seedlings. Planta 240, 687-700.

41. Gu Y, Cao MK, Zhang YQ, Sun Y, Hu WH, Wu CS (2015) Effects of low temperature on photosynthetic fluorescence and enzyme activity of carbon metabolism of maize at booting stage. $J$ Plant Physiol 51, 941-948. 


\section{Appendix A. Supplementary data}

\section{There were 45 varieties in total, and 3 groups of} germination tests were carried out for each variety

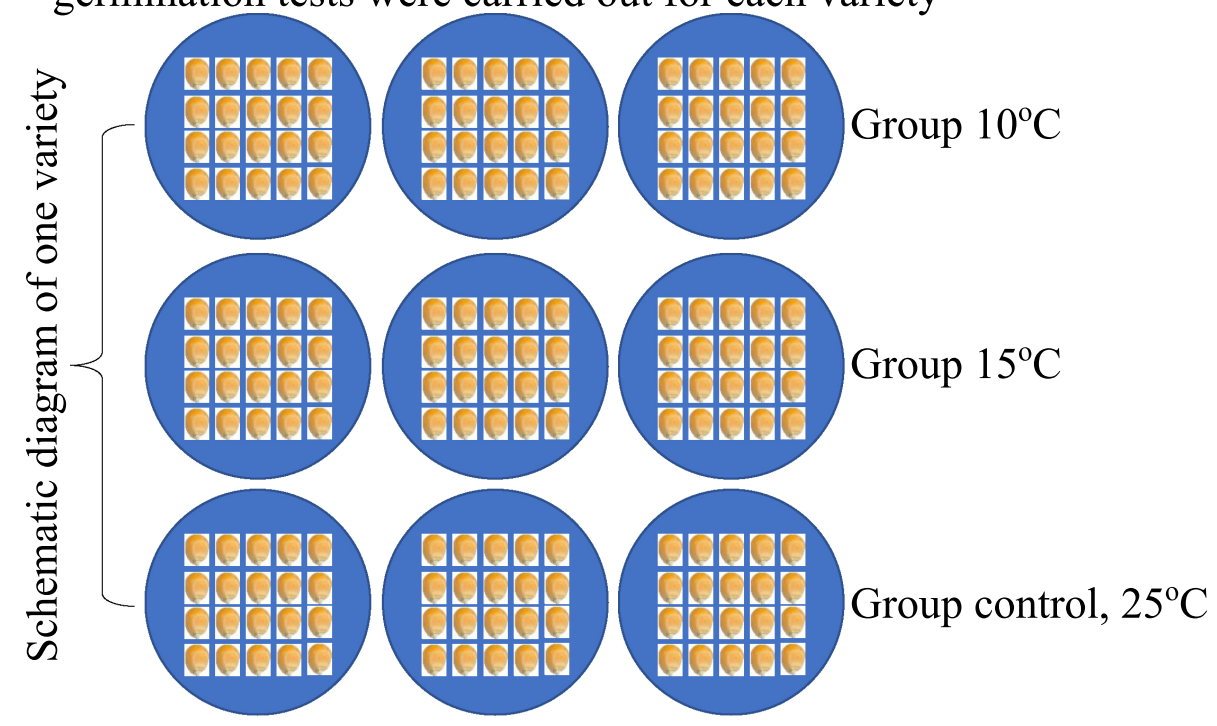

Fig. S1 Experimental design for the germination tests. The circle represents the germination Petri dishes.

cold-tolerant plants (HengYu709) cold-sensitive plants (DongDan213)
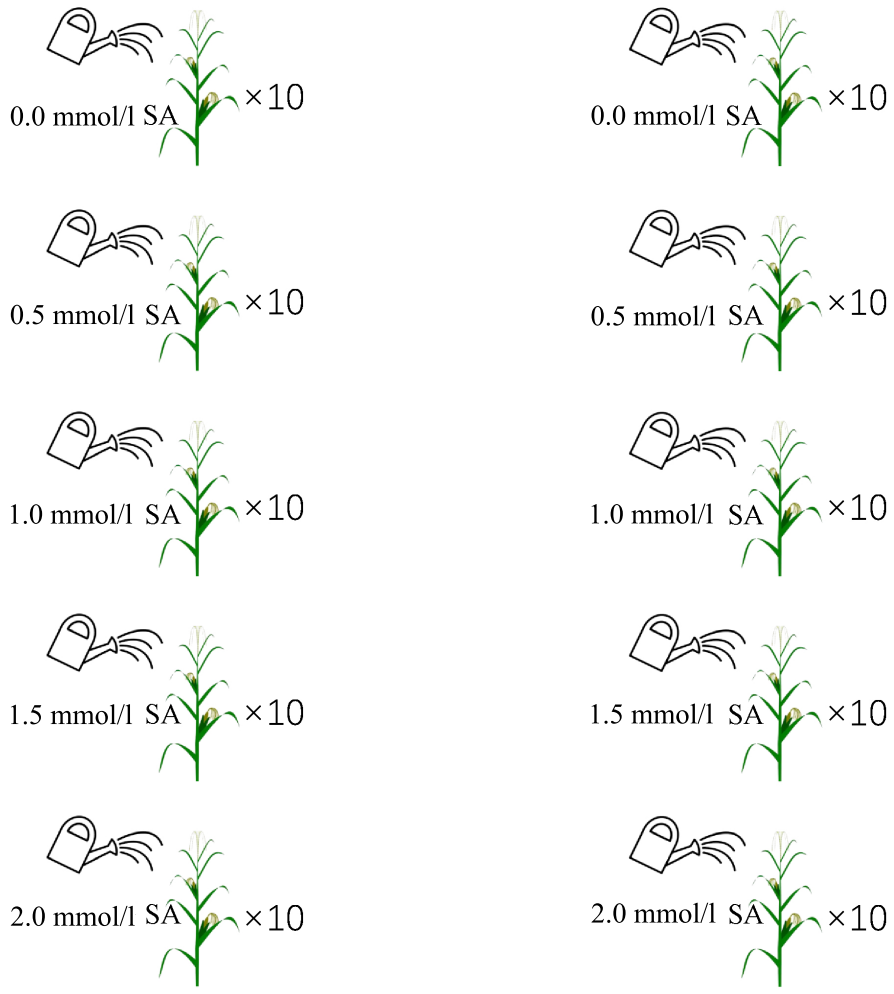

Fig. S2 Experimental design for the salicylic acid (SA) treatment. 
Table S1 Corn germination parameters at different temperatures.

\begin{tabular}{|c|c|c|c|c|c|c|}
\hline \multirow[b]{2}{*}{ Variety } & \multicolumn{3}{|c|}{$15^{\circ} \mathrm{C}$} & \multicolumn{3}{|c|}{$10^{\circ} \mathrm{C}$} \\
\hline & $\begin{array}{l}\text { RTV for GE } \\
\mathrm{V}_{15^{\circ} \mathrm{C}}, \mathrm{V}_{25^{\circ} \mathrm{C}}\end{array}$ & $\begin{array}{l}\text { RTV for GP } \\
\mathrm{V}_{15^{\circ} \mathrm{C}}, \mathrm{V}_{25^{\circ} \mathrm{C}}\end{array}$ & $\begin{array}{l}\text { RTV for GI } \\
\mathrm{V}_{15^{\circ} \mathrm{C}}, \mathrm{V}_{25^{\circ} \mathrm{C}},\end{array}$ & $\begin{array}{l}\text { RTV for GE } \\
\mathrm{V}_{10^{\circ} \mathrm{C}}, \mathrm{V}_{25^{\circ} \mathrm{C}}\end{array}$ & $\begin{array}{l}\text { RTV for GP } \\
\mathrm{V}_{10^{\circ} \mathrm{C}}, \mathrm{V}_{25^{\circ} \mathrm{C}}\end{array}$ & $\begin{array}{l}\text { RTV for GI } \\
\mathrm{V}_{10^{\circ} \mathrm{C}}, \mathrm{V}_{25^{\circ} \mathrm{C}},\end{array}$ \\
\hline DeDan1002 & 105.56 & 96.49 & 121.82 & 31.58 & 61.40 & 54.41 \\
\hline JiSheng385 & 100.00 & 101.75 & 136.92 & 51.16 & 70.18 & 53.43 \\
\hline W1521 & 300.00 & 53.13 & 53.19 & 38.89 & 87.50 & 74.80 \\
\hline HW217 & 39.53 & 108.16 & 176.35 & 52.94 & 89.80 & 73.95 \\
\hline HengYu709 & 51.67 & 105.26 & 207.41 & 183.87 & 103.51 & 91.87 \\
\hline WeiKe3757 & 136.84 & 68.75 & 79.68 & 19.23 & 39.58 & 31.75 \\
\hline YanFeng508 & 108.89 & 91.07 & 141.68 & 63.27 & 80.36 & 58.84 \\
\hline FuYou10 & 258.33 & 43.48 & 57.72 & 38.71 & 56.52 & 46.49 \\
\hline ZhengDan958 & 79.59 & 96.30 & 162.04 & 48.72 & 92.59 & 69.18 \\
\hline ZhongDi77 & 75.68 & 82.69 & 140.04 & 28.57 & 44.23 & 43.87 \\
\hline PingAn185 & 200.00 & 73.58 & 74.57 & 75.00 & 84.91 & 67.08 \\
\hline DongDan213 & 416.67 & 87.23 & 52.60 & 32.00 & 53.19 & 48.41 \\
\hline HeYu3 & 366.67 & 89.13 & 65.49 & 69.70 & 89.13 & 71.47 \\
\hline JunDan6 & 56.76 & 171.88 & 245.26 & 14.29 & 34.38 & 31.53 \\
\hline LiNong24 & 341.67 & 107.41 & 75.05 & 9.76 & 29.63 & 22.29 \\
\hline ChuangShi998 & 50.00 & 123.91 & 122.39 & 155.56 & 58.70 & 59.95 \\
\hline XH84 & 46.67 & 78.57 & 92.98 & 142.86 & 53.57 & 52.78 \\
\hline DaYuM737 & 48.28 & 107.14 & 191.27 & 167.86 & 96.43 & 86.33 \\
\hline LvYu9915 & 90.70 & 101.92 & 159.14 & 53.85 & 78.85 & 60.46 \\
\hline JiNongDa885 & 97.83 & 98.21 & 155.75 & 55.56 & 94.64 & 73.06 \\
\hline TieYan36 & 32.14 & 103.92 & 161.42 & 55.56 & 80.39 & 91.46 \\
\hline LvYu4117 & 116.67 & 20.00 & 27.95 & 0 & 12.50 & 23.35 \\
\hline ChangDan297 & 27.59 & 90.20 & 131.50 & 50.00 & 27.45 & 28.26 \\
\hline JiuDan100 & 81.40 & 108.00 & 155.23 & 45.71 & 72.00 & 49.67 \\
\hline YuLong9 & 95.35 & 94.34 & 140.62 & 12.20 & 67.92 & 46.75 \\
\hline JiDan33 & 106.25 & 106.90 & 103.31 & 35.29 & 20.69 & 26.89 \\
\hline JiDan35 & 107.69 & 98.31 & 124.81 & 33.93 & 76.27 & 51.24 \\
\hline JiDan47 & 100.00 & 100.00 & 171.43 & 78.33 & 93.33 & 72.11 \\
\hline JiDan50 & 123.81 & 51.02 & 76.06 & 53.85 & 38.77 & 40.48 \\
\hline JiDan87 & 109.26 & 93.33 & 126.31 & 57.63 & 88.33 & 63.45 \\
\hline JiDan137 & 92.11 & 74.07 & 106.17 & 25.71 & 29.63 & 27.20 \\
\hline JiDan550 & 101.72 & 98.33 & 149.58 & 52.54 & 90.00 & 62.87 \\
\hline JiDan558 & 101.96 & 91.07 & 130.06 & 32.69 & 82.14 & 56.30 \\
\hline JiDan631 & 106.00 & 100.00 & 139.18 & 39.62 & 74.55 & 50.15 \\
\hline XianYu335 & 192.59 & 62.50 & 88.02 & 17.31 & 28.57 & 22.01 \\
\hline XianYu508 & 162.50 & 94.55 & 101.70 & 5.77 & 16.36 & 11.91 \\
\hline LiangYu88 & 255.56 & 45.65 & 52.88 & 4.35 & 8.70 & 5.48 \\
\hline YuanDan68 & 89.13 & 100.00 & 160.76 & 53.66 & 72.55 & 53.95 \\
\hline YinHe32 & 120.59 & 89.58 & 128.21 & 14.63 & 50.00 & 34.32 \\
\hline MeiHeDa529 & 240.00 & 57.41 & 65.85 & 8.33 & 33.33 & 26.03 \\
\hline LeiAo150 & 130.00 & 92.86 & 124.68 & 1.92 & 8.93 & 5.80 \\
\hline LiangYu99 & 162.50 & 97.30 & 110.75 & 0 & 2.70 & 2.35 \\
\hline LiMin33 & 90.53 & 120.00 & 137.86 & 31.82 & 94.00 & 60.51 \\
\hline YinHe33 & 88.89 & 100.00 & 165.08 & 17.50 & 39.62 & 29.38 \\
\hline LiangYu66 & 100.00 & 87.50 & 111.11 & 3.33 & 4.17 & 7.65 \\
\hline
\end{tabular}

GE, germination energy; GP, germination percentage; and GI, germination index 
Table S2 Membership function (MF) evaluation of corn germination parameters at different temperatures.

\begin{tabular}{|c|c|c|c|c|c|c|}
\hline \multirow{2}{*}{ Variety } & \multicolumn{3}{|c|}{$15^{\circ} \mathrm{C}$} & \multicolumn{3}{|c|}{$10^{\circ} \mathrm{C}$} \\
\hline & MF for GE & MF for GP & MF for GI & MF for GE & MF for GP & MF for GI \\
\hline ChangDan297 & 0.46 & 0 & 0.48 & 0.25 & 0.32 & 0.29 \\
\hline ChuangShi998 & 0.68 & 0.06 & 0.43 & 0.56 & 1.00 & 0.64 \\
\hline DaYuM737 & 0.57 & 0.05 & 0.75 & 0.93 & 1.08 & 0.94 \\
\hline DeDan1002 & 0.50 & 0.20 & 0.43 & 0.58 & 0.20 & 0.58 \\
\hline DongDan213 & 0.44 & 1.00 & 0.11 & 0.50 & 0.21 & 0.51 \\
\hline FuYou10 & 0.15 & 0.59 & 0.14 & 0.03 & 0.25 & 0.49 \\
\hline HengYu709 & 0.56 & 0.06 & 0.83 & 1.00 & 1.18 & 1.00 \\
\hline HeYu3 & 0.46 & 0.87 & 0.17 & 0.86 & 0.45 & 0.77 \\
\hline HW217 & 0.58 & 0.03 & 0.68 & 0.86 & 0.34 & 0.80 \\
\hline JiDan137 & 0.36 & 0.17 & 0.36 & 0.27 & 0.17 & 0.28 \\
\hline JiDan33 & 0.57 & 0.20 & 0.35 & 0.18 & 0.23 & 0.27 \\
\hline JiDan35 & 0.52 & 0.21 & 0.45 & 0.73 & 0.22 & 0.55 \\
\hline JiDan47 & 0.53 & 0.19 & 0.66 & 0.90 & 0.50 & 0.78 \\
\hline JiDan50 & 0.20 & 0.25 & 0.22 & 0.36 & 0.35 & 0.43 \\
\hline JiDan550 & 0.52 & 0.19 & 0.56 & 0.87 & 0.34 & 0.68 \\
\hline JiDan558 & 0.47 & 0.19 & 0.47 & 0.79 & 0.21 & 0.60 \\
\hline JiDan631 & 0.53 & 0.20 & 0.51 & 0.71 & 0.25 & 0.53 \\
\hline JiDan87 & 0.48 & 0.21 & 0.45 & 0.85 & 0.37 & 0.68 \\
\hline JiNongDa885 & 0.51 & 0.18 & 0.59 & 0.91 & 0.36 & 0.79 \\
\hline JiSheng385 & 0.54 & 0.19 & 0.50 & 0.67 & 0.33 & 0.57 \\
\hline JiuDan100 & 0.58 & 0.14 & 0.59 & 0.69 & 0.29 & 0.53 \\
\hline JunDan6 & 1.00 & 0.07 & 1.00 & 0.31 & 0.09 & 0.33 \\
\hline LeiAo150 & 0.48 & 0.26 & 0.45 & 0.06 & 0.01 & 0.04 \\
\hline LiangYu66 & 0.44 & 0.19 & 0.38 & 0.01 & 0.02 & 0.06 \\
\hline LiangYu88 & 0.17 & 0.59 & 0.11 & 0.06 & 0.03 & 0.03 \\
\hline LiangYu99 & 0.51 & 0.35 & 0.38 & 0 & 0 & 0 \\
\hline LiMin33 & 0.66 & 0.16 & 0.51 & 0.91 & 0.2 . & 0.65 \\
\hline LiNong24 & 0.58 & 0.81 & 0.22 & 0.27 & 0.06 & 0.22 \\
\hline LvYu4117 & 0 & 0.23 & 0 & 0.10 & 0 & 0.23 \\
\hline LvYu9915 & 0.54 & 0.16 & 0.60 & 0.76 & 0.35 & 0.65 \\
\hline MeiHeDa529 & 0.25 & 0.55 & 0.17 & 0.30 & 0.05 & 0.26 \\
\hline PingAn185 & 0.35 & 0.44 & 0.21 & 0.82 & 0.48 & 0.72 \\
\hline TieYan36 & 0.55 & 0.01 & 0.61 & 0.77 & 0.36 & 1.00 \\
\hline W1521 & 0.22 & 0.70 & 0.12 & 0.84 & 0.25 & 0.81 \\
\hline WeiKe3757 & 0.32 & 0.28 & 0.24 & 0.37 & 0.12 & 0.33 \\
\hline XH84 & 0.39 & 0.05 & 0.30 & 0.50 & 0.92 & 0.56 \\
\hline XianYu335 & 0.28 & 0.42 & 0.28 & 0.26 & 0.11 & 0.22 \\
\hline XianYu508 & 0.49 & 0.35 & 0.34 & 0.14 & 0.04 & 0.11 \\
\hline YanFeng508 & 0.47 & 0.21 & 0.52 & 0.77 & 0.41 & 0.63 \\
\hline YinHe32 & 0.46 & 0.24 & 0.46 & 0.47 & 0.09 & 0.36 \\
\hline YinHe33 & 0.53 & 0.16 & 0.63 & 0.37 & 0.11 & 0.30 \\
\hline YuanDan68 & 0.53 & 0.16 & 0.61 & 0.69 & 0.34 & 0.58 \\
\hline YuLong9 & 0.49 & 0.17 & 0.52 & 0.65 & 0.08 & 0.50 \\
\hline ZhengDan958 & 0.50 & 0.13 & 0.62 & 0.89 & 0.31 & 0.75 \\
\hline ZhongDi77 & 0.41 & 0.12 & 0.52 & 0.41 & 0.18 & 0.46 \\
\hline
\end{tabular}

GE, germination energy; GP, germination percentage; and GI, germination index 